\title{
CONTEST FOR ATTENTION IN A QUALITY-LADDER MODEL OF ENDOGENOUS GROWTH
}

\author{
VOLKER GROSSMANN
}

CESIFO WORKING PAPER NO. 1003

CAtegory 5: Fiscal POLICY, MACROECONOMICS AND GROWTH August 2003

Presented at CESifo Area Conference on Public Sector Economics, May 2003

\footnotetext{
An electronic version of the paper may be downloaded

- from the SSRN website: Www.SSRN.com

- from the CESifo website: www.CESifo.de
} 


\title{
CONTEST FOR ATTENTION IN A QUALITY-LADDER MODEL OF ENDOGENOUS GROWTH
}

\begin{abstract}
This paper develops a quality-ladder model of endogenous growth to study the interplay between in-house R\&D and marketing expenditure. Although promotional activity is modelled as purely wasteful competition among firms for attention, it unambiguously fosters innovation activity of firms, and possibly, leads to faster growth. This result rests on two premises which are consistent with empirical evidence. First, if firms incur higher sunk costs for marketing, concentration and firm sizes rise. Second, firm size and R\&D expenditure are positively related. As a result, R\&D investments per firm may even become excessive, whereas being inefficiently low in the benchmark case without marketing. This has non-trivial consequences for the socially optimal policy design with respect to R\&D subsidies and entry incentives.
\end{abstract}

JEL Code: O31, O40, H20, L16.

Keywords: contest for attention, endogenous growth, innovation activity, marketing, R\&D subsidies, scale effects.

\author{
Volker Grossmann \\ Socioeconomic Institute \\ University of Zurich \\ Zürichbergstr 14 \\ CH-8032 Zürich \\ Switzerland \\ volker.grossmann@wwi.unizh.ch
}

I am grateful to Josef Falkinger and Volker Meier for detailed comments on an earlier draft. I also benefited from discussions with Henning Bohn, Hartmut Egger, Reto Föllmi, Josef Zweimüller, and seminar participants at the University of Zurich, the CESifo Area Conference on Public Economics 2003, Munich, and the conference on Dynamics, Economic Growth, and International Trade (DEGIT), 2003, Helsinki. 


\section{Introduction}

In a world with complex and differentiated goods, the physical attributes of a product are often difficult to ascertain for consumers before purchasing it. This leaves room for firms to promote such "experience goods" by framing product characteristics in accordance with consumers' desires. This kind of advertising is often related to psychological and sociological aspects, like appealing to desires for social recognition, a trendy lifestyle, and so on. In contrast to "search goods", for which advertising provides information on existence, price, retail location etc. (e.g., Grossman and Shapiro, 1984), advertising on experience goods does not seem to contain much valuable information (e.g., Tirole, 1988). ${ }^{1}$ Rather, it serves to create attention in order to ensure that a product is on the mind of consumers when these choose among several alternatives and thus, to increase the probability of purchase. ${ }^{2}$

This paper analyzes the interplay between marketing and in-house $\mathrm{R} \& \mathrm{D}$ expenditure in a quality-ladder model of endogenous growth. ${ }^{3}$ That is, in addition to investing in quality-improving $\mathrm{R} \& \mathrm{D}$, firms are engaged in a contest for attention of consumers by promoting their products and innovations, respectively. For a single firm, this means that the probability to be successfully perceived as provider of a product of certain quality depends on the amount of marketing investments incurred

\footnotetext{
${ }^{1}$ The distinction between search goods and experience goods is adopted from the IO literature on advertising. It is well-known that advertising spending on experience goods, which is the focus of the present paper, is much higher than on search goods (e.g., Nelson, 1974).

${ }^{2}$ For instance, firms design advertising campaigns, do market research, and train their sales personnel in order to communicate product characteristics more successfully to potential customers. Recently, new information technologies have allowed firms to assemble, store and analyze customer data like demographics and purchase habits ('data mining'). In turn, the so-created customer databases ('data warehouses') enable marketing managers to design and keep track of marketing campaigns and to target consumers more effectively than by mass-media advertising (Bresnahan, 1999). In fact, 'new direct marketing' and 'database marketing' are recent headlines in the fastgrowing business literature on these issues (e.g., Shepard and Batra, 1998). See also Shapiro and Varian (1999), who provide many examples.

${ }^{3}$ The benchmark model without marketing roughly follows Young (1998).
} 
relative to its rivals. ${ }^{4}$ This implies that the contest among firms for the attention of consumers is a form of wasteful competition.

Nevertheless, it is shown that the relationship of marketing activity in the economy to R\&D investments per firm is unambiguously positive. This rather surprising result rests on two premises. First, higher sunk costs of firms for marketing fosters concentration (as measured, for instance, by the sum of the shares of a certain number of top firms), and thus, leads to larger firms on average. This is due to the assumption that firms can freely enter the economy but have to cover costs incurred for both marketing and R\&D by profits from monopolistic product market competition. ${ }^{5}$ Second, the assumptions of the model imply a positive relationship between firm size and R\&D expenditure. That is, if a firm expects its market share to increase for given $R \& D$ effort of firms, its incentive to invest in $R \& D$ is raised. These two premises give rise to the following mechanism. If firms increase their marketing spending in response to an increase in the effectiveness of marketing, concentration and firm sizes increase ceteris paribus. In turn, this fosters innovation activity per firm.

However, total R\&D expenditure in the economy is unaffected by higher promotional activity due to the decline in the number of firms. Consequently, the implications of marketing for the economy's growth rate depend on the role of the number of innovating firms (which is positively related to population size and thus, to the scale of the economy) for intertemporal knowledge spillovers, and thus, for long-run growth. If there are no scale effects with respect to growth, then marketing spending and growth are positively related. However, in the presence of scale effects, higher technological incentives to invest in marketing may lead to slower growth.

\footnotetext{
${ }^{4}$ The terms "marketing" and "advertising" are used interchangably throughout the paper. Various notions of these terms exist in the literature. In this paper, their meaning is exclusively confined to attention-creating activities in the sense that the probability of a firm to be perceived as high-quality producer is an increasing function of its relative spending level for these tasks.

${ }^{5}$ Treating marketing outlays as endogenous sunk costs borrows from the theoretical IO literature on the relationship between advertising and market structure (e.g., Shaked and Sutton, 1987; Sutton, 1991).
} 
The two fundamental hypotheses for the main mechanism of the model, which give rise to a positive relationship between advertising activity in the economy and R\&D activity per firm, are supported by empirical evidence. First, empirical studies have frequently reported a highly positive relationship between advertising expenditure levels (as shares of total sales revenues) and industry concentration (e.g., Mueller and Rogers, 1984; Sutton, 1991). Indeed, overall advertising costs are quite sizable in many industries. For instance, according to Schonfeld \& Associates (2003), for consumer products as a whole, the U.S. advertising-to-sales ratio in 2002 was 6.7 percent. ${ }^{6}$ Thus, the frequently suggested empirical relevance of advertising levels as important determinant for average firm size and concentration in an industry is not surprising. Second, at least in advanced countries (which are the ones primarily conducting original $\mathrm{R} \& \mathrm{D}$ rather than imitating), firm size and $\mathrm{R} \& \mathrm{D}$ expenditure are strongly positively related (see, e.g., Cohen and Levin, 1989, and Cohen and Klepper, 1996, as well as the references therein). For instance, as shown in Table 1, 84.7 percent of business R\&D expenditure in the U.S. in 1997 have been incurred by firms with more than 500 employees. This figure is not much lower if we look at firms with over 1000 employees, which still account for 81.6 percent of total expenditure on innovation activity. In other countries, the importance of large firms for R\&D activity is somewhat less pronounced. However, for most countries, about two thirds of R\&D outlays can be attributed to firms with more than 500 employees, and well above 50 percent to firms with more than 1000 employees. $^{7}$

\footnotetext{
${ }^{6}$ For all sectors in the economy combined, the respective figure was 2.9 percent. For the UK, Paton and Conant (2001) report that the mean advertising-to-sales ratio in 1999 was 3.25 percent for consumer manufacturing and 2.38 percent for all sectors combined. The pharmaceutical industry is an example for a sector which is characterized by both high advertising intensity and high R\&D intensity.

${ }^{7}$ Note that the observed relationship between firm size and innovation activity is not due to a government bias of public R\&D financing towards larger firms. The share of government-financed business R\&D is rarely over 10 percent and in some countries even biased to small companies (e.g., in Belgium, Finland and Switzerland). However, the U.S. subsidizes companies with more than 500 employees somewhat more than companies with less than 500 employees, with a share of 16.3
} 
Table 1: Percentages of total business R\&D by large firms in selected countries (year in brackets)

\begin{tabular}{|c|c|c|}
\hline & $>500$ employees & $>1000$ employees \\
\hline Australia (1996) & 49.5 & 35.5 \\
\hline Belgium (1995) & 63.7 & 51.4 \\
\hline Canada (1995) & 65.4 & 55.8 \\
\hline Finland (1997) & 70.7 & 56.2 \\
\hline France (1995) & 79.6 & 70.0 \\
\hline Italy (1995) & 80.2 & 65.1 \\
\hline Spain (1995) & 52.0 & 34.7 \\
\hline Switzerland (1996) & 69.6 & 58.3 \\
\hline United Kingdom (1997) & 71.1 & 58.6 \\
\hline United States (1997) & 84.7 & 81.6 \\
\hline
\end{tabular}

Source: OECD (1999, Tab. 5.4.1).

Note: Only advanced countries with comparable databases are included. 
What are the welfare effects and policy implications of the relationship between marketing investments, concentration, R\&D activity, and economic growth? According to the model, welfare is basically determined by two arguments, the number of varieties available to consumers and (for given initial quality levels) the growth rate of average quality of these products. In absence of marketing, the presence of positive spillover effects of R\&D imply that, compared to the social optimum, innovation activity is too low in equilibrium and the number of firms is too high. ${ }^{8}$ In this case, the government can implement the first-best allocation by providing $R \mathscr{E} D$ subsidies together with a lump-sum tax on firms. However, if we allow for marketing activity, R\&D investments and growth may even become excessive and product variety too low. Hence, the optimal policy design may now require to encourage entry (e.g., by a franchise subsidy) rather than taxing it. Moreover, although innovation activity of firms may now become excessive, R\&D subsidies should be even higher than in the case without marketing. This is because higher entry incentives not only lead to an increase in the number of firms but also to a reduction in firm sizes and thus, to less innovation activity per firm. ${ }^{9}$

In sum, the analysis suggests that there are important general equilibrium interactions between marketing and R\&D incentives of firms. Neglecting these interactions may give rise to misleading conclusions regarding over- or underinvestment in R\&D and the socially optimal policy design towards both R\&D and entry of firms.

The paper is organized as follows. Section 2 sets up the basic structure of the model and analyzes the equilibrium. In particular, it is explored whether the contest vs. 9.2 percent of total R\&D spending in 1997 (see OECD, 1999; Tab. 5.4.2).

${ }^{8}$ There is no "creative destruction effect" (e.g., Aghion and Howitt, 1992) or "stepping on toes effect" (Jones and Williams, 2000) in the model, which would distort R\&D decisions towards overinvestment. This allows us to focus on the role of marketing by starting from an underinvestment benchmark.

${ }^{9}$ It should be noted, however, that in the present model this policy design can be optimal only in a second-best sense if firms incur advertising costs. This is because advertising creates negative externalities among firms, which cannot be fully internalized without further instruments. However, as briefly discussed in section 4, more appropriate measures may be politically infeasible. 
for attention among firms crowds out innovation activity of firms or complements it. Section 3 compares the market equilibrium with the social planning solution. Section 4 examines how the socially optimal policy design for encouraging $R \& D$ is affected by marketing incentives of firms. Section 5 discusses the role of scale effects regarding the economy's growth rate for the results. The last section concludes. All proofs are relegated to an appendix.

\section{The Model}

\subsection{Model Structure}

Consider an economy which is populated by $L$ individuals with infinite lifetimes, each supplying one unit of labor in each period $t=0,1,2, \ldots$ (i.e., there is no population growth). The labor market is perfect and the wage rate is normalized to unity, $w_{t}=1$. There is a representative consumer with intertemporal utility function

$$
U=\sum_{t=0}^{\infty} \rho^{t} \ln C_{t},
$$

$0<\rho<1 . C_{t}$ is a consumption index, which is given by

$$
C_{t}=\left(\int_{0}^{n_{t}}\left(q_{t}(i) x_{t}(i)\right)^{\frac{\sigma-1}{\sigma}} d i\right)^{\frac{\sigma}{\sigma-1}},
$$

$\sigma>1 . x_{t}(i)$ denotes the quantity of good $i \in \mathcal{N}_{t} \equiv\left[0, n_{t}\right]$ consumed in period $t$, whereas $q_{t}(i)$ is referred to as its perceived quality. The latter can be affected by marketing and R\&D activities. From the perspective of single firms, the outcome of these activities exhibits uncertainty, as specified below. Firms are risk-neutral, each producing one variety of a horizontally differentiated product in monopolistic competition. The measure $n_{t}$ is referred to as the "number of firms" in $t$ and is endogenously determined.

Firms have a constant-returns to scale production technology with labor as single input:

$$
x_{t}(i)=b l_{t}^{P}(i)
$$


where $l_{t}^{P}(i)$ denotes the amount of production-related labor employed in firm $i \in \mathcal{N}_{t}$ at date $t$, i.e., unit costs are given by $1 / b>0$.

Following Young (1998), firms can incur (in-house) R\&D labor investments in order to improve product quality one period in advance of production. ${ }^{10}$ Moreover, the quality as perceived by consumers also depends on the firm's performance in a contest for attention. For the moment, let this effect be represented by a random variable $\gamma_{t}(i)$ discussed later. Perceived product quality $q_{t}(i)$ of variety $i$ in any period $t>0$ evolves according to

$$
q_{t}(i)=\left\{\begin{array}{cl}
\bar{S}_{t-1} \gamma_{t}(i) g\left(l_{t-1}^{R}(i)\right) & \text { if } g\left(l_{t-1}^{R}(i)\right) \geq 1 \\
\bar{S}_{t-1} \gamma_{t}(i) & \text { otherwise }
\end{array}\right.
$$

where $l_{t-1}^{R}(i)$ denotes R\&D labor investment of firm $i \in \mathcal{N}_{t}$ in period $t-1$ and $g(\cdot)$ is an increasing function. Moreover,

$$
\bar{S}_{t-1}=\bar{S}_{t-2} \frac{1}{n_{t-1}} \int_{0}^{n_{t-1}} g\left(l_{t-2}^{R}(i)\right) d i
$$

reflects an intertemporal knowledge spillover effect from previous investments of firms in R\&D. ${ }^{11}$ Under intertemporal spillover (5), if all firms invest the same amount of labor at date $t-2$ in R\&D, i.e., if $l_{t-2}^{R}(i)=l_{t-2}^{R}$ for all $i$, we have $\bar{S}_{t-1}=\bar{S}_{t-2} g\left(l_{t-2}^{R}\right)$. That is, $n_{t-1}$ (i.e., the number of those firms which invest in period $t-2$ and produce final output in $t-1$ ) does not matter for research capabilities of firms in the subsequent period. This assumption reflects the notion of Young (1998) that innovations of firms are "equivalent" in the sense that firms come up with similar solutions to similar problems at the same time. As will become apparent, this eliminates the feature of many endogenous growth models that the economy's

\footnotetext{
${ }^{10}$ As discussed in section 4 (see Remark 2), the specifications in Young (1998) are different from those in the present model, also leading to fundamentally different policy implications. Moreover, Young does not consider marketing, which is the main focus of the present paper. For other quality-ladder growth models, see e.g., Grossman and Helpman (1991) and Aghion and Howitt (1992).

${ }^{11}$ Regarding intellectual property rights, (4) and (5) imply that innovations are proprietary knowledge for one period only.
} 
growth rate depends on population size $L$ ("scale effect"). The role of scale effects for the results are discussed in section 5 .

The number of firms $n_{0}$ in the initial period is historically given. Moreover, for simplicity, assume $q_{0}(i)=\bar{S}_{0}>0$ for product quality of any firm $i \in \mathcal{N}_{0}$ which produces final output in the initial period. Also specify

$$
g\left(l^{R}\right)=\left(l^{R}\right)^{\kappa}
$$

$0<\kappa<1$. The parameter $\kappa$ is referred to as the "effectiveness of R\&D".

In contrast to previous growth models, firms may promote their products and innovations by incurring marketing expenditure. More specifically, firms engage in a contest for attention (e.g., by framing product characteristics in accordance with consumers' desires). That is, the probability of being successful depends on a firm's advertising expenditure relative to those of its rivals. This borrows from the game-theoretic literature on contests (Skaperdas, 1996).

Formally, let $\gamma_{t}(i) \in \Gamma \subseteq \mathbb{R}_{+}$in (4) be a random variable with c.d.f. $Q\left(\gamma_{t}(i) ; z_{t-1}(i)\right)$, where $z_{t-1}(i)=l_{t-1}^{M}(i) / \bar{l}_{t-1}^{M} . l_{t-1}^{M}(i)$ denotes the amount of marketing labor employed by firm $i \in \mathcal{N}_{t}$ and

$$
\bar{l}_{t-1}^{M}=\frac{1}{n_{t}} \int_{0}^{n_{t}} l_{t-1}^{M}(i) d i
$$

is the average amount of marketing labor in $t-1, t \geq 1$. Let $Q\left(\cdot ; z_{t-1}(i)\right)$ be twice continuously differentiable in $z$. The following assumption implies that, from the perspective of a single firm, an increase in marketing effort relative to its rivals shifts probability mass towards high realizations of $\gamma$. That is, the c.d.f. of the perceived quality of a firm's product is shifted according to first-order stochastic dominance.

Assumption 1. For all $\gamma, \partial Q(\gamma ; z) / \partial z \leq 0$.

Note that, if all firms allocate the same amount of labor to advertising (i.e., if $l_{t-1}^{M}(i)=\bar{l}_{t-1}^{M}>0$ for all $\left.i\right)$, no firm gains compared to a situation without marketing. Thus, the contest for attention gives rise to a "rat race" situation, i.e., marketing creates negative externalities. 
For later use in the analysis of the impact of marketing on expected profits of firms, define the function

$$
h(z) \equiv\left(\int_{\Gamma} \gamma^{\sigma-1} d Q(\gamma ; z)\right)^{\frac{1}{\sigma-1}}
$$

with normalization $h(1)=1$. We can then define the elasticity

$$
\tilde{\eta}(z) \equiv z h^{\prime}(z) / h(z) \text { with } \tilde{\eta}(1)=h^{\prime}(1) \equiv \eta
$$

Assumption 1 guarantees $h^{\prime}(\cdot) \geq 0$ and thus, $\eta \geq 0 .{ }^{12}$ Throughout the paper, the parameter $\eta$ is called the "effectiveness of marketing". The following restrictions on the parameters of the model are imposed.

Assumption 2. Let (i) $\kappa(\sigma-1) f \geq 1-(\kappa+\eta)(\sigma-1)>0$, and (ii) $\kappa(\sigma-1) f \geq$ $1-\kappa(\sigma-1)-\rho>0$.

As will become apparent, the first (weak) inequality in part (i) of Assumption 2 implies $l_{t-1}^{R}(i) \geq 1$ for all $i, t>0$, in market equilibrium with symmetric investments in $\mathrm{R} \& \mathrm{D}$ and marketing, whereas the second (strict) inequality ensures existence of such an equilibrium. Part (ii) ensures the analogous for a social planning solution.

There is free entry of firms into the economy, with a large number of potential entrants. At all times, firms have to incur a fixed labor requirement $f>0$ prior to production, which may be thought of being related to red tape or the organization of production. Note that, as $f$ has to be incurred each period and the intertemporal spillover effect cannot be appropriated by firms, each firm's planning horizon is exactly one period in advance (Young, 1998). In $t-1$, each firm $i \in \mathcal{N}_{t}$ (producing final output in period $t$ ) issues bonds or shares in a perfect financial market in order to finance fixed costs $f$, as well as $\mathrm{R} \& \mathrm{D}$ and marketing investments $l_{t-1}^{R}(i)$ and $l_{t-1}^{M}(i)$, respectively.

\footnotetext{
${ }^{12}$ Under Assumption $1, \int_{\Gamma} v(\gamma) d Q(\gamma ; z)$ is nondecreasing in $z$ for any nondecreasing function $v$ : $\Gamma \rightarrow \mathbb{R}$ (see, e.g., Athey, 2000).
} 


\subsection{General Equilibrium}

The representative consumer's budget constraint in period $t \geq 0$ reads $^{13}$

$$
A_{t+1}=\left(1+r_{t}\right) A_{t}+L-E_{t}
$$

where $A_{t}$ denotes the value of asset holdings in $t, E_{t}$ is consumption expenditure, and $r_{t}$ is the interest rate between $t-1$ and $t$.

Maximization of utility (1), (2) subject to (10) implies that consumption spending evolves according to Euler equation

$$
E_{t}=\left(1+r_{t}\right) \rho E_{t-1}
$$

$t>0$. Moreover, the demand function for good $i$ in period $t$ is given by

$$
x_{t}^{D}(i)=q_{t}(i)^{\sigma-1} \frac{E_{t}}{P_{t}}\left(\frac{p_{t}(i)}{P_{t}}\right)^{-\sigma},
$$

where $p_{t}(i)$ is the price of good $i$ in $t$. The price index

$$
P_{t} \equiv\left(\int_{0}^{n_{t}}\left(\frac{p_{t}(i)}{q_{t}(i)}\right)^{1-\sigma} d i\right)^{\frac{1}{1-\sigma}}
$$

is defined in a way that the CES-index $C_{t}$, defined in (2), equals real consumption expenditure in period $t$, i.e., we have $C_{t}=E_{t} / P_{t}$. As will become apparent, the multiplicative form of demand functions (12), together with free entry and the sunk cost nature of marketing outlays, imply a positive relationship between marketing spending in the economy and innovation activity of a firm.

Profits of firm $i$ in period $t$ are given by $\pi_{t}(i)=\left(p_{t}(i)-1 / b\right) x_{t}^{D}(i)$. Thus, output prices are set according to the well-known formula

$$
p_{t}(i)=\frac{\sigma}{\sigma-1} \frac{1}{b} \equiv p
$$

\footnotetext{
${ }^{13}$ Recall $w_{t}=1$. Initial income from asset holdings $\left(1+r_{0}\right) A_{0}$ is exogenously given. In addition to budget constraint (10), the representative consumer also has to observe both a standard transversality condition, which is given by $\lim _{T \rightarrow \infty} A_{T+1} / \prod_{t=1}^{T}\left(1+r_{t}\right)=0$, and non-negativity constraints, $E_{t} \geq 0, A_{t+1} \geq 0, t \geq 0$.
} 
for all $t \geq 0$ (Dixit and Stiglitz, 1977). Provided that $g\left(l_{t-1}^{R}(i)\right) \geq 1$ (as will become apparent, this is consistent with an equilibrium under part (i) of Assumption 2), under rational expectations, at time $t-1$, each firm $i \in \mathcal{N}_{t}$ chooses non-production labor investments $l_{t-1}^{R}(i)$ and $l_{t-1}^{M}(i)$ to maximize its expected firm value

$$
\frac{p_{t}(i)-1 / b}{1+r_{t}} \mathbb{E}\left(x_{t}^{D}(i) \mid l_{t-1}^{R}(i), l_{t-1}^{M}(i)\right)-l_{t-1}^{R}(i)-l_{t-1}^{M}(i)-f,
$$

where

$$
\mathbb{E}\left(x_{t}^{D}(i) \mid l_{t-1}^{R}(i), l_{t-1}^{M}(i)\right)=\left[\bar{S}_{t-1} g\left(l_{t-1}^{R}(i)\right) h\left(\frac{l_{t-1}^{M}(i)}{\bar{l}_{t-1}^{M}}\right)\right]^{\sigma-1} \frac{E_{t}}{P_{t}}\left(\frac{p_{t}(i)}{P_{t}}\right)^{-\sigma}
$$

is expected demand of a firm conditional on its investments $(\mathbb{E}$ is the expectation operator). ${ }^{14}$ Next, the equilibrium concept is defined (which also serves the purpose to summarize notation).

Definition 1. (Equilibrium). An equilibrium is a sequence $\left\{E_{t}, A_{t+1}, n_{t+1}\right\}$ of aggregate consumption spending, asset holdings and the number of firms, a sequence $\left\{r_{t+1}, P_{t}\right\}$ of interest rates and price indices, a sequence $\left\{x_{t}(i), l_{t}^{P}(i), p_{t}(i)\right\}$ of output levels, production employment levels and output prices of firms $i \in \mathcal{N}_{t}$, and a sequence $\left\{q_{t+1}(i), l_{t}^{R}(i), l_{t}^{M}(i)\right\}$ of perceived quality levels, R\&D and marketing employment levels of firms $i \in \mathcal{N}_{t+1}, t=0,1,2, \ldots$, which satisfy the following conditions:

(E1) Given $\left(1+r_{0}\right) A_{0}, r_{t+1}, n_{t}$ and $p_{t}(i)$, for any $t \geq 0, E_{t}, A_{t+1}$ and $x_{t}(i)$ maximize the representative household's utility (1), (2) subject to (10), $i \in \mathcal{N}_{t}$.

(E2) Given $P_{t}, E_{t}$ and $q_{t}(i)$, for any $t \geq 0, p_{t}(i)$ maximizes $\left(p_{t}(i)-1 / b\right) x_{t}^{D}(i)$ s.t. $(12), i \in \mathcal{N}_{t}$; given $P_{t}, \bar{l}_{t-1}^{M}, E_{t}, r_{t}$ and $\bar{S}_{t-1}$, for any $t>0, l_{t-1}^{R}(i)$ and $l_{t-1}^{M}(i)$ maximize expected firm value $(15), i \in \mathcal{N}_{t}$.

\footnotetext{
${ }^{14}$ Substitute (4) in (12) and use $h(z){ }^{\sigma-1}=\int_{\Gamma} \gamma^{\sigma-1} d Q(\gamma ; z)$ from (8) to obtain (16). Note that each single firm has measure zero (i.e., there are no strategic interactions among firms). Thus, like in the framework of Dixit and Stiglitz (1977), $P_{t}$ and $E_{t}$ are taken as given in the optimization problem of firms. In the present context, firms also take average marketing employment $\bar{l}_{t-1}^{M}$ as given.
} 
(E3) Given $P_{t}, \bar{l}_{t-1}^{M}, E_{t}, r_{t}$ and $\bar{S}_{t-1}$, for any $t>0$, the expected firm value (15) of $\left(p_{t}(i), l_{t-1}^{R}(i), l_{t-1}^{M}(i)\right), i \in \mathcal{N}_{t}$, equals zero (free entry).

(E4) For any $t \geq 0, x_{t}(i)=b l_{t}^{P}(i)=q_{t}(i)^{\sigma-1} E_{t} p_{t}(i)^{-\sigma} /\left(P_{t}\right)^{1-\sigma}, i \in \mathcal{N}_{t}($ goods market equilibrium). rium).

(E5) For any $t>0, \int_{0}^{n_{t-1}} l_{t-1}^{P}(i) d i+n_{t}\left(l_{t-1}^{R}+l_{t-1}^{M}+f\right)=L$ (labor market equilib-

(E6) For any $t \geq 0,\left(1+r_{t}\right) A_{t}=\int_{0}^{n_{t}}\left(p_{t}(i)-1 / b\right) \mathbb{E}\left(x_{t}^{D}(i) \mid l_{t-1}^{R}(i), l_{t-1}^{M}(i)\right) d i$ (asset market equilibrium). ${ }^{15}$

(E7) $l_{t-1}^{R}(i)=l_{t-1}^{R}$ and $l_{t-1}^{M}(i)=l_{t-1}^{M}$ for all $i \in \mathcal{N}_{t}, t>0 .{ }^{16}$

Suppose that $\mathbb{E}\left(x_{t}^{D}(i) \mid l_{t-1}^{R}(i), l_{t-1}^{M}(i)\right)$ and thus, objective function (15) is strictly concave as function of $\left(l_{t-1}^{R}(i), l_{t-1}^{M}(i)\right){ }^{17}$ Using (14)-(16) and observing symmetry condition (E7), the first-order conditions regarding optimal R\&D and marketing effort are given by

$$
\frac{p-1 / b}{1+r_{t}} \mathbb{E}\left(x_{t}^{D} \mid l_{t-1}^{R}, l_{t-1}^{M}\right)(\sigma-1) \frac{g^{\prime}\left(l_{t-1}^{R}\right)}{g\left(l_{t-1}^{R}\right)}=1
$$

(stated as equality since we focus on $g\left(l_{t-1}^{R}\right) \geq 1$, and thus, $l_{t-1}^{R}>0$ ) and

$$
\frac{p-1 / b}{1+r_{t}} \mathbb{E}\left(x_{t}^{D} \mid l_{t-1}^{R}, l_{t-1}^{M}\right)(\sigma-1) \frac{h^{\prime}(1)}{h(1)} \frac{1}{\bar{l}_{t-1}^{M}} \leq 1,
$$

${ }^{15}$ To see (E6), note that the expected value of firm $i \in \mathcal{N}_{t}$ at date $t$, denoted $v_{t}(i)$, is given by the asset market equilibrium equation $r_{t}=\mathbb{E}\left(\pi_{t}(i)\right) / v_{t}(i)+\left(v_{t+1}(i)-v_{t}(i)\right) / v_{t}(i)$, i.e., the rate of return in the capital market (which is certain as consumers can perfectly diversify their portfolios and there is no macroeconomic risk) equals the expected dividend yield plus capital gains. As sunk cost have to be incurred each period, $v_{t+1}(i)=0$ and thus, $v_{t}(i)=\mathbb{E}\left(\pi_{t}(i)\right) /\left(1+r_{t}\right)$. Finally, use $\mathbb{E}\left(\pi_{t}(i)\right)=\left(p_{t}(i)-1 / b\right) \mathbb{E}\left(x_{t}^{D}(i) \mid \cdot\right)$ and $A_{t}=\int_{0}^{n_{t}} v_{t}(i) d i$.

${ }^{16}$ Since firms are identical ex ante, the analysis focusses on symmetric non-production employment levels for R\&D and marketing activities. However, note that ex post firms are necessarily dissimilar with respect to output, production employment and profits in equilibrium as demand for their products is uncertain.

${ }^{17}$ This is fulfilled, for instance, if $h(z)=z^{\eta}$, due to $(\kappa+\eta)(\sigma-1)<1$ from part (i) of Assumption 2. 
with equality if $l_{t-1}^{M}>0$, respectively. The left-hand sides of (17) and (18) equal the marginal benefit of $\mathrm{R} \& \mathrm{D}$ and marketing employment, respectively, whereas the right-hand sides equal marginal costs (recall $w_{t}=1$ ). If $l_{t-1}^{M}=\bar{l}_{t-1}^{M}>0$, by using (6) and (9), first-order conditions (17) and (18) imply

$$
\frac{l_{t-1}^{M}}{l_{t-1}^{R}}=\frac{\eta}{\kappa}
$$

It is easy to check from (16), together with (6) and (9), that $\kappa(\sigma-1)$ and $\eta(\sigma-1)$ equal the (constant) elasticity of expected product demand $\mathbb{E}\left(x_{t}^{D}(i) \mid \cdot\right)$ with respect to R\&D and marketing investments, the latter being evaluated at $l_{t-1}^{M}(i)=\bar{l}_{t-1}^{M}$, respectively. Hence, the ratio of marketing employment to $R \& D$ employment in any firm is time-invariant, decreases with the effectiveness of $\mathrm{R} \& \mathrm{D}, \kappa$, and increases with the effectiveness of marketing, $\eta$. In a similar fashion as in Young (1998), the following can be shown. (All results are proven in Appendix.)

Lemma 1. The equilibrium interest rate immediately jumps to a steady state level, with $r_{t}=(1-\rho) / \rho \equiv \tilde{r}$ for all $t>0$.

The absence of transitional dynamics in the model is due to the linear spillover effect in the evolution of perceived quality (4). (It is also due to the absence of physical capital, of course.) The following result emerges.

Proposition 1. (Equilibrium). In market equilibrium, we have:

(i) For any $t>0, R \mathscr{E} D$ labor and marketing labor per firm are given by

$$
l_{t-1}^{R}=\frac{\kappa(\sigma-1) f}{1-(\kappa+\eta)(\sigma-1)} \equiv \tilde{l}^{R}
$$

and

$$
l_{t-1}^{M}=\frac{\eta(\sigma-1) f}{1-(\kappa+\eta)(\sigma-1)} \equiv \tilde{l}^{M},
$$

respectively, and the number of firms is

$$
n_{t}=\frac{\rho L[1-(\kappa+\eta)(\sigma-1)]}{f(\sigma-1+\rho)} \equiv \tilde{n}
$$


(ii) For any $t>1$, the (approximate) growth rate $\vartheta_{t} \equiv \ln \left(c_{t} / c_{t-1}\right)$ of real consumption per capita $c_{t} \equiv C_{t} / L$ is given by

$$
\begin{aligned}
\vartheta_{t} & =\ln g\left(\tilde{l}^{R}\right) \\
& =\kappa \ln \left(\frac{\kappa(\sigma-1) f}{1-(\kappa+\eta)(\sigma-1)}\right) \equiv \tilde{\vartheta}
\end{aligned}
$$

(iii) Intertemporal utility $(\tilde{U})$ is given by

$$
\tilde{U}=\frac{\rho}{1-\rho}\left(\frac{1}{\sigma-1} \ln \tilde{n}+\frac{1}{1-\rho} \tilde{\vartheta}\right)+\Lambda
$$

where $\Lambda \equiv(\sigma-1)^{-1} \ln n_{0}+(1-\rho)^{-1} \ln \left[\bar{S}_{0}(\sigma-1) b L /(\sigma-1+\rho)\right]$.

According to (24), welfare can be subdivided in two main components. First, $\tilde{U}$ positively depends on the equilibrium number of firms $\tilde{n}$, given by (22), due to the "love-of-variety" property of preferences (Dixit and Stiglitz, 1977). Second, $\tilde{U}$ is positively related to the (approximate) growth rate $\tilde{\vartheta}$ of the economy, which is given by (23). Note that $\tilde{\vartheta} \geq 0$, according to part (i) of Assumption 2. Also note that $\tilde{\vartheta}$ is independent of $L$, i.e., growth does not exhibit scale effects, in analogy to Young (1998).

\subsection{Comparative Statics}

This subsection derives comparative-static results for changes in the effectiveness of marketing and $\mathrm{R} \& \mathrm{D}, \eta$ and $\kappa$, respectively. Changes in $\eta$ are of particular interest. Since $\tilde{l}^{M}=0$ if and only if $\eta=0$, according to (21), and since standard growth models do not allow for marketing investments of firms, $\eta=0$ serves as a benchmark case. Thus, by considering changes in $\eta$, one can examine, for instance, whether marketing possibilities crowd out R\&D investments, in turn necessarily reducing growth, or if they complement innovation activity. In addition, changes in $\kappa$ are considered to obtain further insights regarding the interplay between $R \& D$ and marketing incentives in the model.

Proposition 2. (Comparative-static results). 
(i) An increase in the effectiveness of marketing or RED , $\eta$ or $\kappa$, respectively, raises both RED and marketing labor per firm ( $\tilde{l}^{R}$ and $\left.\tilde{l}^{M}\right)$ as well as the growth rate $(\tilde{\vartheta})$, but reduces the number of firms $(\tilde{n})$.

(ii) An increase in $\eta$ raises aggregate marketing employment $\tilde{L}^{M} \equiv \tilde{n} \tilde{l}^{M}$ in the economy without affecting aggregate R\&D employment $\tilde{L}^{R} \equiv \tilde{n} \tilde{l}^{R}$. Similarly, an increase in $\kappa$ raises $\tilde{L}^{R}$ but does not affect $\tilde{L}^{M}$.

(iii) An increase in $\eta$ unambiguously lowers welfare $\tilde{U}$. Moreover, if $\eta(\sigma-1) \leq \rho$, $\tilde{U}$ is increasing in $\kappa$; if $\eta(\sigma-1)>\rho$, the impact of an increase in $\kappa$ on $\tilde{U}$ is ambiguous.

Behind these comparative-static results, the following mechanisms are at work. First, an increase in $\eta$ or $\kappa$ raises the incentive of firms to incur sunk cost for marketing and R\&D, respectively, for any given number of firms $n$. Thus, an increase in $\kappa$ raises the amount of researchers per firm $\tilde{l}^{R}$, and in view of (23), also raises the growth rate of real consumption $\tilde{\vartheta}$. Moreover, $\tilde{l}^{M}$ rises with $\eta$. Hence, for any $n$, an increase in $\eta$ or $\kappa$ has a negative impact on the expected firm value. Consequently, less firms enter the economy, i.e., $\tilde{n}$ declines.

This leads us to a main result of this paper: whereas it is not surprising that an increase in $\eta$ raises $\tilde{l}^{M}$, it also unambiguously raises R\&D employment per firm $\tilde{l}^{R}{ }^{18}$ (Similarly, an increase in $\kappa$ raises $\tilde{l}^{M}$.) This result is driven by the following mechanism. First, due to free entry and the sunk cost nature of advertising outlays, an increase in $\eta$ raises expected product demand $\mathbb{E}\left(x_{t}^{D} \mid \cdot\right)$ of entrants (as firms rationally expect a larger market share), holding $\mathrm{R} \& \mathrm{D}$ effort of firms constant. In turn, the expected return to R\&D (which is given by the left-hand side of (17)) increases. This leads firms to increase R\&D investments.

As outlined in the introduction, this mechanism is consistent with empirical

\footnotetext{
${ }^{18}$ Notably, this result does not depend on the specification of $g(\cdot)$ in $(6)$. To see this, note that $\kappa=g^{\prime}\left(l^{R}\right) l^{R} / g\left(l^{R}\right)$. Using the latter expression, (20) reveals that $\tilde{l}^{R}$ is increasing in $\eta$ whenever an equilibrium with symmetric non-production labor investments exists. (Under (6), existence of such an equilibrium has been ensured by part (i) of Assumption 2.)
} 
evidence; that is, advertising expenditure seems to be a crucial determinant of concentration patterns, and firm size is strongly related to R\&D spending of firms. In turn, also the economy's growth rate $\tilde{\vartheta}$ is rising in $\eta$. As discussed in section 5 , however, the impact of both $\eta$ and $\kappa$ on long-run growth crucially depend on specification (5) of the knowledge spillover, and thus, on the role of scale effects.

Remark 1. (Firm size and R\&D). One may object that the symmetry of R\&D investments in the model does not allow to refer to a positive firm size-R\&D relationship in the data. However, the symmetry assumption is merely made for simplicity in order to study general equilibrium effects of advertising in a tractable framework. To see this, suppose that there are two types of firms, entering the economy in certain shares without knowing their type in advance. Suppose firms differ in their research productivity and let $A$ and $B$ be the sets of firms with high and low research productivity, respectively. Let quality-improvements evolve according to $q_{t}(i)=\xi \bar{S}_{t-1} g\left(l_{t-1}^{R}(i)\right)$ for all $i \in A$ and $q_{t}(i)=\bar{S}_{t-1} g\left(l_{t-1}^{R}(i)\right)$ for all $i \in B, \xi>1$. (Again, we focus on $g\left(l_{t-1}^{R}(i)\right) \geq 1$ for all $i$ but now neglect marketing for simplicity.) One can show that this not only implies that, given both types invest the same amount in $\mathrm{R} \& \mathrm{D}$, firms in $A$ have higher demand (and thus, are larger in terms of output or sales) than firms in $B$, but also that firms in $A$ invest more in R\&D. (In contrast, if $q_{t}(i)=\xi \bar{S}_{t-1} g\left(l_{t-1}^{R}(i)\right)$ for all $i$, then R\&D investments become independent of $\xi$.) From this, one can conclude that the basic property of the model that $R \& D$ investments are positively related to firm size does not hinge on the symmetry of firms with respect to innovation activity.

In order to explore how $\eta$ and $\kappa$ affect total attention-creating and innovation activity in the economy, aggregate employment levels in marketing and R\&D are considered next. Note that, according to part (ii) of Proposition 2, $\kappa$ does not affect $\tilde{L}^{M}$ and $\eta$ has no impact on $\tilde{L}^{R}$. This is because of two opposing effects which can be deducted from the preceding results. For instance, consider the impact of an increase in $\eta$ on $\tilde{L}^{R}=\tilde{n} \tilde{l}^{R}$. On the one hand, R\&D employment per firm $\tilde{l}^{R}$ rises with $\eta$. On the other hand, however, the number of firms $\tilde{n}$ declines with $\eta$. Under 
the specifications of the model, both effects exactly cancel. Moreover, since the impact of, say, an increase in $\eta$ on $\tilde{l}^{M}$ is more pronounced than on $\tilde{l}^{R}$, we find that $\eta$ and $\tilde{L}^{M}$ are positively related. Analogously, an increase in $\kappa$ raises $\tilde{L}^{R}$.

Finally, regarding efficiency, both $\eta$ or $\kappa$ affect welfare $\tilde{U}$ through $\tilde{n}$ and $\tilde{\vartheta}$ in opposite directions. According to part (iii) of Proposition 2, the net effect of a higher $\kappa$ on welfare $\tilde{U}$ is positive, if the elasticity $\eta(\sigma-1)$ of expected product demand $\mathbb{E}\left(x_{t}^{D}(i) \mid \cdot\right)$ with respect to $l_{t-1}^{M}(i)$, evaluated at $l_{t-1}^{M}(i)=\bar{l}_{t-1}^{M}$, is sufficiently low. (Otherwise, the effect is ambiguous.) The impact of a higher $\eta$ on $\tilde{U}$ is definitely negative.

\section{Social Optimum}

Marketing activities of single firms exert negative (static) externalities to their rivals. Thus, a social planner would set $l^{M}=0$ for all firms at all times. Before the socially optimal policy design is discussed (in the next section), it is intriguing to compare the market solution with the social planning optimum.

Proposition 3. (Social optimum). The socially optimal levels of R\&D labor per firm $\left(l^{R *}\right)$, marketing labor per firm $\left(l^{M *}\right)$, and the number of firms $\left(n^{*}\right)$ are given by $y^{19}$

$$
\begin{gathered}
l^{R *}=\frac{\kappa(\sigma-1) f}{1-\kappa(\sigma-1)-\rho}, \\
l^{M *}=0,
\end{gathered}
$$

and

$$
n^{*}=\frac{\rho L(1-\kappa(\sigma-1)-\rho)}{f(1-\rho)(\sigma-1+\rho)},
$$

respectively. Thus, the optimal growth rate is given by $\vartheta^{*} \equiv \ln g\left(l^{R *}\right)$.

\footnotetext{
${ }^{19}$ Note that $l^{R *} \geq 1$, and thus, $\vartheta^{*} \geq 0$, according to part (ii) of Assumption 2.
} 
First, consider the market equilibrium in absence of marketing opportunities for firms, i.e., $\eta=0$. As carefully discussed by Young (1998), since firms cannot appropriate the intertemporal spillover effect, firms underinvest in R\&D (i.e., $\left.\tilde{l}^{R}<l^{R *}\right)$ and growth is too low in this benchmark case, compared with the social optimum. Correspondingly, the number of firms in market equilibrium is excessive (i.e., $\tilde{n}>n^{*}$ ). More generally, however, comparing (20) and (25) implies the following.

Corollary 1. (Market equilibrium vs. social optimum). $\tilde{l}^{R}>(=,<) l^{R *}$ if and only if $\eta(\sigma-1)>(=,<) \rho$.

Remember that the equilibrium R\&D investment per firm, $\tilde{l}^{R}$, increases with the effectiveness of marketing $\eta$. As a result, if $\eta$ is high, firms may even overinvest in $\mathrm{R} \& \mathrm{D}$ compared with the social optimum (i.e., $\left.\tilde{l}^{R}>l^{R *}\right) \cdot{ }^{20}$ Thus, according to (23), also the long-run growth rate may become excessive (i.e., $\tilde{\vartheta}>\vartheta^{*}$ ). ${ }^{21}$ Besides $\tilde{l}^{R}>l^{R *}$, also $\tilde{n}<n^{*}$ is possible if $\eta$ is sufficiently high (compare (22) and (27)), i.e. variety may become too low.

\section{Optimal Policy Design}

In view of the previous section, it is interesting to examine how the socially optimal policy design towards R\&D and entry depends on the effectiveness of marketing $\eta$.

\footnotetext{
${ }^{20}$ However, recall from Proposition 2 that welfare $\tilde{U}$ is always decreasing in $\eta$. For instance, if $\eta(\sigma-1)=\rho$ (which means that the equilibrium growth rate $\tilde{\vartheta}$ is at its socially optimal level), the number of firms is too low in market equilibrium, according to (22) and (27).

${ }^{21}$ Jones and Williams (2000) investigate whether a decentralized economy undertakes too little or too much R\&D in calibrating an endogenous growth model which incorporates several distortions to R\&D suggested by the existing literature. According to their analysis, underinvestment in R\&D typically prevails. In another interesting recent paper, Alvarez-Pelaez and Groth (2003) show that there may be too much R\&D in the growth framework of Romer (1990) if one disentangles the market power parameter from the capital share parameter in this model. However, the authors point out that parameter values have to be quite unrealistic to obtain excess R\&D.
} 
Moreover, it is explored how the effectiveness of $\mathrm{R} \& \mathrm{D}, \kappa$, affects optimal policy.

Consider the following tax-transfer scheme. Each firm $i \in \mathcal{N}_{t}$ obtains a transfer

$$
T\left(l_{t-1}^{R}(i)\right)=\tau l_{t-1}^{R}(i)-\Theta
$$

in $t-1$, if it spends $l_{t-1}^{R}(i)$ on $\mathrm{R} \& \mathrm{D}$ labor. $\tau$ is the $\mathrm{R} \& \mathrm{D}$ subsidy rate and $\Theta>(<) 0$ can be thought of being a lump-sum franchise tax (subsidy), i.e., a disincentive (an incentive) for firms to enter the economy (Konishi, 1990). The total transfer to firms from the scheme in (28) is financed by lump-sum taxation of consumers, where the government's budget is balanced each period.

As will be seen below, for the benchmark case $\eta=0$, it is possible to implement the first-best allocation under appropriate choice of $\tau$ and $\Theta$. Thus, if $\eta=0$, it is sufficient to focus on the simple scheme (28) with two parameters. It should be stressed, however, that the policy design for $\eta>0$ can be "socially optimal" only in a second-best sense. As $l^{M *}=0$ according to Proposition 3, clearly, the first-best policy would include to ban advertising. However, this may be politically infeasible. As a matter of fact, although economists agree that advertising on experience goods is a waste of resources (consistent with our modelling strategy), there are little restrictions on advertising in reality. ${ }^{22}$

Deriving the decentralized equilibrium under (28) analogously to section 2.2 , one obtains equilibrium levels of R\&D labor and marketing labor per firm, $\tilde{l}^{R}$ and $\tilde{l}^{M}$, as well as the number of firms, $\tilde{n}$, as functions of policy parameters $\tau$ and $\Theta$. In addition to the comparative-static results in Proposition 2 (which are still valid), the following effects of policy parameters can be derived. ${ }^{23}$

\footnotetext{
${ }^{22}$ Exceptions include advertising restrictions on alcoholic beverages or cigarettes, related to protection of young people. Generally, however, policy makers may face severe informational problems, e.g., are unable to distinguish informative from wasteful advertising at reasonable administrative costs. More fundamentally, general bans on advertising also seem to be in conflict with freedom of speech.

${ }^{23}$ Recall that all proofs are relegated to the appendix. In appendix (see Remark 3), it is also shown that the government's budget is automatically balanced under the considered tax-transfer
} 
Lemma 2. Under the tax-transfer scheme (28), an increase in $\tau$ or $\Theta$ raises $\tilde{l}^{R}$ and reduces $\tilde{n}$. Moreover, if $\eta>0, \tilde{l}^{M}$ increases in $\Theta$ and does not depend on $\tau$.

An increase in the $\mathrm{R} \& \mathrm{D}$ subsidy rate $\tau$ reduces marginal costs of $\mathrm{R} \& \mathrm{D}$ labor, and, thus, gives an incentive to firms to raise sunk cost for innovation activity. The net effect of $\tau$ on the equilibrium number of firms $\tilde{n}$ is negative. An increase in $\Theta$ raises entry costs, thus also reducing $\tilde{n}$. Moreover, as firms rationally expect their market share to increase with $\Theta$, all other things equal, the return to R\&D is raised. Thus, $\tilde{l}^{R}$ increases with $\Theta$. For the same reason, the amount of marketing labor per firm $\tilde{l}^{M}$ is positively related to $\Theta$. However, the $\mathrm{R} \& \mathrm{D}$ subsidy rate $\tau$ does not affect $\tilde{l}^{M}$, for the following reason. On the one hand, if $\eta>0$, the two non-production activities within a firm are positively related, according to (19). As $\tilde{l}^{R}$ increases with $\tau$, this implies a positive effect of $\tau$ on $\tilde{l}^{M}$. On the other hand, however, an increase in $\tau$ reduces marginal costs of $\mathrm{R} \& \mathrm{D}$ effort relative to those of marketing effort, which has a counteracting effect on $\tilde{l}^{M} \cdot{ }^{24}$ Both effects exactly cancel.

Remark 2. (Relation to Young, 1998). In contrast to our finding of a positive impact of an increase of $\tau$ on $\tilde{l}^{R}$ in Lemma 2, the analysis of Young (1998) suggests that "the provision of proportional $\mathrm{R} \& \mathrm{D}$ subsidies [...] will be ineffective (in growth rates)" (p. 52). To gain insight regarding this striking difference in policy implications, note that under tax-transfer scheme (28), the first-order condition with respect to $R \& D$ labor can be written as

$$
\frac{p-1 / b}{1+r_{t}} \mathbb{E}\left(x_{t}^{D} \mid l_{t-1}^{R}, l_{t-1}^{M}\right)(\sigma-1) \frac{g^{\prime}\left(l_{t-1}^{R}\right)}{g\left(l_{t-1}^{R}\right)}=1-\tau
$$

(analogously to (17)). Moreover, free entry now implies

$$
\frac{p-1 / b}{1+r_{t}} \mathbb{E}\left(x_{t}^{D} \mid l_{t-1}^{R}, l_{t-1}^{M}\right)=(1-\tau) l_{t}^{R}+l_{t}^{M}+f+\Theta .
$$

Combining (29) and (30) leads to

$$
\frac{(\sigma-1) g^{\prime}\left(l_{t-1}^{R}\right)}{g\left(l_{t-1}^{R}\right)}=\frac{1-\tau}{(1-\tau) l_{t-1}^{R}+l_{t-1}^{M}+f+\Theta} .
$$

scheme when financed by lump-sum taxation of consumers.

${ }^{24}$ Note that marginal cost of R\&D under tax-transfer scheme (28) become $1-\tau$ (replacing the right-hand side of first-order condition (17)). Thus, replace (19) by $l_{t-1}^{M} / l_{t-1}^{R}=\eta(1-\tau) / \kappa$. 
Effectively, Young (1998) specifies $l_{t}^{M}=f=\Theta \equiv 0$, indeed implying that equilibrium $\mathrm{R} \& \mathrm{D}$ labor per firm is independent of $\tau$, according to (31). Moreover, using our notation, in his model $g\left(l^{R}\right)=\mu^{-1} \ln \left(l^{R} / F\right)$ ( $\mu$ and $F$ are positive numbers) and $\gamma_{t}(i) \equiv 1$. Thus, quality remains unchanged in Young's model if $l^{R} \leq F e^{\mu} \equiv \hat{l}^{R}$. The threshold amount of research labor per firm, $\hat{l}^{R}$, which must be exceeded to obtain positive growth is interpreted as "standard production fixed costs" (p. 47). In contrast, in the present model such costs are reflected by the fixed labor requirement $f>0$ for opening up a firm, as usual in monopolistic competition models. In this case, R\&D subsidies generally do foster innovations. ${ }^{25}$

Lemma 2 will prove helpful for understanding the socially optimal policy design. Denote by $\tilde{l}^{R}(\tau, \Theta)$ and $\tilde{n}(\tau, \Theta)$ the equilibrium values of $\mathrm{R} \& \mathrm{D}$ labor per firm and the number of firms, respectively, resulting under tax-transfer scheme (28). One can then state the following.

Proposition 4. (Optimal Policy Design). Denote by $\left(\tau^{*}, \Theta^{*}\right)$ the optimal policy design under (28). We have:

(i) If $\eta=0$, then $\tau^{*}=\rho$ and $\Theta^{*}>0$. Moreover, $\left(\tau^{*}, \Theta^{*}\right)$ implement the first-best solution, i.e., $\tilde{l}^{R}\left(\tau^{*}, \Theta^{*}\right)=l^{R *}$ and $\tilde{n}\left(\tau^{*}, \Theta^{*}\right)=n^{*}$.

(ii) $\Theta^{*}$ decreases with $\eta$; in particular, there exists a critical level $\bar{\eta}>0$ such that $\Theta^{*}<0$ if $\eta>\bar{\eta}$. Moreover, $\partial \Theta^{*} / \partial \kappa<(=,>) 0$ if and only if $\eta(\sigma-1)>(=,<) \rho$.

(iii) $\tau^{*}$ increases with $\eta$ and does not depend on $\kappa$.

In the absence of marketing (i.e., $\eta=0$ ), since welfare basically consists of two (endogenous) components, product variety $n$ and the rate of growth $\vartheta$ (see Proposition 1), two policy parameters are sufficient for implementing the first-best allocation (which is characterized in Proposition 3). Since, from a social point of view, growth is too low and variety is too high in market equilibrium with $\eta=0$, it

\footnotetext{
${ }^{25}$ See Howitt (1999) for a Schumpeterian growth model, which incorporates the basic idea of Young (1998) in order to eliminate scale effects concerning the growth rate. Also in his model, R\&D subsidies imply faster growth.
} 
is optimal to provide a positive incentive to innovate in combination with a negative incentive to enter the economy. In view of Lemma 2, this is reached by choosing $\tau^{*}>0$ and $\Theta^{*}>0$, which explains part (i) of Proposition 4.

Parts (ii) and (iii) answer the question how the optimal tax-transfer scheme depends on the effectiveness of marketing and $\mathrm{R} \& \mathrm{D}, \eta$ and $\kappa$, respectively. In particular, part (ii) says that allowing firms to advertise their products (i.e., $\eta>0$ ) may require a regime switch in public policy; that is, if $\eta$ exceeds some critical level $\bar{\eta}>0$, it is optimal to encourage entry (i.e., to set $\Theta^{*}<0$ ) rather than discourage it. More generally, as a high $\eta$ is associated with low product variety (according to part (i) of Proposition 2), the optimal entry tax $\Theta^{*}$ should decrease with $\eta$. As the decrease in firm sizes triggered by a lower $\Theta$ discourages innovation effort in each firm, this policy response to an increase in $\eta$ should be combined with an increase in the optimal $\mathrm{R} \& \mathrm{D}$ subsidy rate $\tau^{*}{ }^{26}$

Due to the fact that $\kappa$ is associated with a positive intertemporal externality while $\eta$ is associated with a negative, static one, a change in $\kappa$ has quite different implications for the optimal policy mix $\left(\tau^{*}, \Theta^{*}\right)$ than a shift in $\eta$. Recall from Lemma 2 that innovation incentives can be enhanced by reducing entry incentives (i.e., by raising $\Theta$ ). From Corollary 1 , if $\eta(\sigma-1)>\rho$, then R\&D investment per firm is excessive from a social point of view (i.e., $\tilde{l}^{R}>l^{R *}$ ). Consequently, in this case, $\Theta^{*}$ should decrease with $\kappa$. In contrast, if $\eta(\sigma-1)<\rho$ and thus, $\tilde{l}^{R}<l^{R *}$, then $\Theta^{*}$ should increase with $\kappa$. Given the optimal choice of $\Theta$, the optimal subsidy rate $\tau^{*}$ is independent of $\kappa \cdot{ }^{27}$

\footnotetext{
${ }^{26}$ In order to confirm that $\tau$ should increase with $\eta$ only if combined with a decrease in $\Theta$, it is worthwhile to consider the optimal $\mathrm{R} \& \mathrm{D}$ subsidy if the goverment is restricted to $\Theta=0$. It can be shown that the "optimal" R\&D subsidy rate under restriction $\Theta=0$, denoted $\tilde{\tau}^{*}$, is given by $\tilde{\tau}^{*}=\rho(\sigma-1+\rho) /[\sigma-1+\rho(1-\kappa(\sigma-1))]$. Whereas $\tau^{*}$ is increasing in $\eta, \tilde{\tau}^{*}$ is independent of $\eta$.

${ }^{27}$ According to $\left(\right.$ A.29) in appendix, we have $\tau^{*}=\rho(1+\eta) /(1+\rho \eta)$, i.e., $\tau^{*} \in[\rho, 1)$. Note that with the usual calibration of the time preference rate $\rho$ of being close to unity, this implies that the optimal $R \& D$ subsidy rate is quite high in the present framework.
} 


\section{Growth: With or Without Scale Effects?}

According to (23), the steady state growth rate $\tilde{\vartheta}$ does not depend on market size $L$, i.e., there is no scale effect regarding growth. ${ }^{28}$ This section examines the role of this appealing property, or more generally, the role of scale effects for the relationship of the equilibrium growth rate $\tilde{\vartheta}$ to the effectiveness of marketing and R\&D, $\eta$ and $\kappa$, respectively. Moreover, it is explored how the socially optimal allocation and optimal policy design, derived in section 3 and 4 , respectively, change if scale effects are present.

For instance, replace intertemporal knowledge spillover (5) by

$$
\bar{S}_{t-1}=\bar{S}_{t-2} \int_{0}^{n_{t-1}} g\left(l_{t-2}^{R}(i)\right) d i .
$$

That is, if $l_{t-2}^{R}(i)=l_{t-2}^{R}$ for all $i$, we have $\bar{S}_{t-1}=\bar{S}_{t-2} n_{t-1} g\left(l_{t-2}^{R}\right){ }^{29}$ Thus, under symmetric investments, the number of firms now affects average goods quality and thus, the economy's growth rate in equilibrium. As the equilibrium number of firms, $\tilde{n}$, positively depends on population size $L$, according to (22), this means that there are now scale effects regarding growth. This modification implies the following.

Proposition 5. (Modified knowledge spillover). Under spillover effect (32).

(i) An increase in $\eta$ reduces the steady state growth rate $\tilde{\vartheta}$, whereas the impact of an increase in $\kappa$ on $\tilde{\vartheta}$ is ambiguous.

(ii) The socially optimal levels of REDD labor per firm $\left(l^{R * *}\right)$ and the number of firms $\left(n^{* *}\right)$ fulfill $l^{R * *}<l^{R *}$ and $n^{* *}>n^{*}$, respectively.

\footnotetext{
${ }^{28}$ However, there is a positive scale effect with respect to the level of equilibrium real consumption expenditure per capita (denoted $\tilde{c}_{t}$ ), since the equilibrium number of firms $\tilde{n}$ is positively related to $L$, according to $(22)$. (One can show that $\tilde{c}_{t}=b \bar{S}_{0} g\left(\tilde{l}^{R}\right)^{t} \tilde{n}^{1 /(\sigma-1)}(\sigma-1) /(\sigma-1+\rho)$, which is increasing in $\tilde{n}$, and thus, also increasing in $L$.) For a more general discussion of scale effects in endogenous growth models, see Jones $(1995,1999)$. Actually, the title of section 5 is adopted from Jones (1999).

${ }^{29}$ Because firms cannot appropriate the intertemporal spillover effect, the allocation of resources in market equilibrium remains unchanged.
} 
(iii) For all $\eta \geq 0$, the socially optimal policy under tax-transfer scheme (28), characterized by $\left(\tau^{* *}, \Theta^{* *}\right)$, fulfill $\Theta^{* *}<0, \Theta^{* *}<\Theta^{*}$ and $\tau^{* *}=\tau^{*} . \Theta^{* *}$ is decreasing in $\eta$ and increasing in $\kappa$.

Recall from part (i) of Proposition 2 that an increase in the effectiveness of marketing or R\&D, $\eta$ or $\kappa$, respectively, raises $\mathrm{R} \& \mathrm{D}$ input $\tilde{l}^{R}$ but lowers the equilibrium number of firms $\tilde{n}$. With respect to a change in $\kappa$, as both effects go in opposite directions, the impact of $\kappa$ on $\tilde{\vartheta}$ is generally ambiguous. ${ }^{30}$ With respect to a change in $\eta$, the effect through the number of firms dominates under (32), i.e., $\tilde{\vartheta}$ decreases with $\eta$. Note that these results are in sharp contrast to the positive relationship of $\eta$ or $\kappa$ to $\tilde{\vartheta}$ in the absence of scale effects, as implied by (23).

On the normative side, compared to the social optimum under the previous specification of knowledge spillovers (5), more firms should enter the economy (i.e., $\left.n^{* *}>n^{*}\right)$. Again, this is because the number of innovating firms now matters for growth under symmetric investments. Correspondingly, R\&D labor per firm should be lower (i.e., $\left.l^{R * *}<l^{R *}\right)$. For the optimal policy mix $\left(\tau^{* *}, \Theta^{* *}\right)$, this implies the following. First, the government should provide higher entry incentives than under the previous specification (5) (i.e., $\left.\Theta^{* *}<\Theta^{*}\right)$. In fact, under (32), entry should now always be subsidized (i.e., $\Theta^{* *}<0$ even for $\eta=0$ ). Second, there is no reason to provide a different $\mathrm{R} \& \mathrm{D}$ subsidy rate than in the basic model (i.e., $\tau^{* *}=\tau^{*}$ ). Also note that the optimal policy responses to changes in $\eta$ or $\kappa$ remain qualitatively the same as derived in Proposition 4.

\section{Conclusion}

This paper has examined the implications of a contest among firms for the attention of consumers in a quality-ladder model of endogenous growth with unrestricted entry. Consistent with the widely-accepted view that advertising on experience goods does not provide consumers with much valuable information, this contest has

\footnotetext{
${ }^{30}$ As shown in appendix, (32) implies $\vartheta_{t}=\kappa \ln \tilde{l}^{R}+\ln \tilde{n} \equiv \tilde{\vartheta}$ for all $t>1$.
} 
been modelled as wasteful competition. ${ }^{31}$

Nevertheless, it has been shown that R\&D investment per firm increases with the effectiveness of marketing. However, due to a simultaneous increase in concentration, total innovation activity is unaffected. The mechanism for these results rests on two fundamental premises, which are consistent with empirical evidence. First, marketing activity is positively related to firm size and concentration, since marketing expenditure constitute sunk costs for firms. Second, firm size is positively related to $R \& D$ activity.

The hypothesis of a positive relationship between marketing spending, $R \& D$ investments and concentration suggested by the analysis is a clear-cut empirical prediction. Sutton (1991) argues that empirical models have to take into account that both advertising ratios and concentration are endogenous variables. The present theory not only underlines this fact, but also adds an additional link of these variables to R\&D activity. ${ }^{32}$

Moreover, the model suggests a link between marketing activity, growth and welfare. If growth does not exhibit scale effects, the analysis implies that the economy's growth rate rises unambiguously with the effectiveness of marketing. To the contrary, if there are scale effects, growth may as well decline. In any case, welfare decreases due to the negative relationship between marketing expenditure and product variety.

Finally, the proposed theory suggests that neglecting the role of marketing expenditures for innovation activity, firm sizes, and growth may lead to misleading policy conclusions. It has been shown that, if growth does not exhibit scale effects and advertising incentives are negligible, the socially optimal policy is to levy a lumpsum tax on firms in combination with a subsidy on R\&D investments. However, if

\footnotetext{
${ }^{31}$ As experience goods tend to be highly differentiated and complex products, one may argue that an analysis of advertising for these goods has a natural place in an innovation model.

${ }^{32}$ Although the basic mechanisms of the theory developed in this research seem to be empirically relevant and plausible, due to potential endogeneity problems suggested by the analysis, a rigorous empirical test has to be carefully designed.
} 
marketing incentives are high or if scale effects regarding the economy's growth rate are substantial, entry should be subsidized. Moreover, because higher entry incentives reduce $R \& D$ spending per firm by lowering firm sizes, R\&D subsidies should increase if the effectiveness of marketing rises.

\section{Appendix}

Proof of Lemma 1. According to (4), (13), (14) and (16), average product demand, evaluated at equilibrium levels, reads

$$
\mathbb{E}\left(x_{t}^{D} \mid l_{t-1}^{R}, l_{t-1}^{M}\right)=\frac{E_{t}}{p n_{t}} .
$$

Using Euler equation (11) and (14) then leads to

$$
\frac{p-1 / b}{1+r_{t}} \mathbb{E}\left(x_{t}^{D} \mid l_{t-1}^{R}, l_{t-1}^{M}\right)=\frac{\rho}{\sigma} \frac{E_{t-1}}{n_{t}} .
$$

Substituting (A.2) into (15) and observing the free entry condition (E3) yields

$$
n_{t}\left(l_{t-1}^{R}+l_{t-1}^{M}+f\right)=\frac{\rho}{\sigma} E_{t-1}
$$

$t>0$. Moreover, as aggregate output in $t-1$ must equal aggregate product demand $E_{t-1} / p$, we have

$$
\int_{0}^{n_{t-1}} l_{t-1}^{P}(i) d i=E_{t-1} \frac{\sigma-1}{\sigma},
$$

according to (3) and (14). Using (A.3) and (A.4), the labor market clearing condition (E5) implies that aggregate consumption spending is given by

$$
E_{t-1} \equiv \tilde{E}=\frac{\sigma L}{\sigma-1+\rho}
$$

for all $t>0$. (11) then implies that the interest rate factor is given by $1+r_{t}=1 / \rho$ for all $t>0$, as in Young (1998). This concludes the proof.

Proof of Proposition 1. First, substitute (A.2) into (17) which yields

$$
\frac{\rho E_{t-1}}{\sigma n_{t}} \frac{(\sigma-1) g^{\prime}\left(l_{t-1}^{R}\right)}{g\left(l_{t-1}^{R}\right)}=1 .
$$


Substituting (A.3) into (A.6), using (6) and, for $\eta>0$, also (19), and rearranging terms proves (20). (If $\eta=0$, set $l_{t-1}^{M}=0$ in (A.3).) To find (21), use (19) and (20). Moreover, substituting (20) and (A.5) into (A.6), using (6), and rearranging terms gives (22). This proves part (i). To obtain (23) in part (ii), first note that for any two firms $i$ and $j, l_{t}^{P}(i) / l_{t}^{P}(j)=\left(\gamma_{t}(i) / \gamma_{t}(j)\right)^{\sigma-1}, t \geq 0$, according to (4), (14), and equilibrium condition (E4). Thus, the ratio

$$
\frac{l_{t}^{P}(i)}{\gamma_{t}(i)^{\sigma-1}} \equiv \theta_{t}
$$

must be the same for all firms $i \in \mathcal{N}_{t}, t \geq 0$. Using (3), (4), and (A.7), for all $t>0$, we have

$$
\begin{aligned}
C_{t} & =b \bar{S}_{t-1} g\left(l_{t-1}^{R}\right)\left(\int_{0}^{n_{t}}\left(\gamma_{t}(i) l_{t}^{P}(i)\right)^{\frac{\sigma-1}{\sigma}} d i\right)^{\frac{\sigma}{\sigma-1}} \\
& =b \bar{S}_{t-1} g\left(l_{t-1}^{R}\right) \theta_{t}\left(\int_{0}^{n_{t}} \gamma_{t}(i)^{\sigma-1} d i\right)^{\frac{\sigma}{\sigma-1}} \\
& =b \bar{S}_{t-1} g\left(l_{t-1}^{R}\right) \theta_{t} n_{t}^{\frac{\sigma}{\sigma-1}}
\end{aligned}
$$

according to $(2)$. (Remember $h(1)=\left(\int_{\Gamma} \gamma^{\sigma-1} d Q(\gamma ; 1)\right)^{\frac{1}{\sigma-1}}=1$.) (A.7) also implies that, for any $t \geq 0$, aggregate production employment $\int_{0}^{n_{t}} l_{t}^{P}(i) d i$ is given by

$$
\begin{aligned}
\int_{0}^{n_{t}} l_{t}^{P}(i) d i & =\theta_{t}\left(\int_{0}^{n_{t}}\left(\gamma_{t}(i)^{\sigma-1} d i\right)\right. \\
& =\theta_{t} n_{t} .
\end{aligned}
$$

Recall that, in equilibrium, $l_{t-1}^{R}=\tilde{l}^{R}$ and $n_{t}=\tilde{n}$ for any $t>0$. Also note that, for any $t>0$,

$$
\int_{0}^{n_{t}} l_{t}^{P}(i) d i=\frac{\sigma-1}{\sigma} \tilde{E},
$$

according to (A.4) and (A.5). Combining (A.8)-(A.10) and observing both (4) and (5) yields equilibrium levels

$$
\tilde{C}_{t}=b \bar{S}_{0} g\left(\tilde{l}^{R}\right)^{t} \tilde{n}^{\frac{1}{\sigma-1}} \frac{\sigma-1}{\sigma} \tilde{E}
$$


for any $t>0$. Analogously, observing $q_{0}(i)=\bar{S}_{0}$ for all $i \in \mathcal{N}_{0}$, we have

$$
\tilde{C}_{0}=b \bar{S}_{0}\left(n_{0}\right)^{\frac{1}{\sigma-1}} \frac{\sigma-1}{\sigma} \tilde{E}
$$

according to (2). Finally, use (A.11) and observe (6) for the second equation in (23) to prove part (ii). To prove part (iii), substitute (A.11) and (A.12) into (1) to obtain

$$
\begin{aligned}
\tilde{U} & =\frac{\ln n_{0}}{\sigma-1}+\sum_{t=0}^{\infty} \rho^{t} \ln \left(\frac{\bar{S}_{0} b(\sigma-1) \tilde{E}}{\sigma}\right)+\sum_{t=1}^{\infty} \rho^{t}\left(\frac{\ln \tilde{n}}{\sigma-1}+t \ln g\left(\tilde{l}^{R}\right)\right)( \\
& =\frac{\ln n_{0}}{\sigma-1}+\frac{1}{1-\rho}\left(\ln \left(\frac{\bar{S}_{0} b(\sigma-1) \tilde{E}}{\sigma}\right)+\frac{\rho \ln \tilde{n}}{\sigma-1}+\frac{\rho}{1-\rho} \ln g\left(\tilde{l}^{R}\right)\right)
\end{aligned}
$$

where $\sum_{t=0}^{\infty} \rho^{t}=1 /(1-\rho)$ and $\sum_{t=1}^{\infty} \rho^{t} t=\rho /(1-\rho)^{2}$ have been used for the latter equation. Substituting (A.5) into (A.13) and observing (23) gives (24). This concludes the proof.

Proof of Proposition 2. Part (i) directly follows from (20)-(23). To prove part (ii), note that

$$
\tilde{L}^{R}=\tilde{n} \tilde{l}^{R}=\frac{\rho \kappa(\sigma-1)}{\sigma-1+\rho}
$$

according to (20) and (22), and

$$
\tilde{L}^{M}=\tilde{n} \tilde{l}^{R}=\frac{\rho \eta(\sigma-1)}{\sigma-1+\rho} .
$$

according to (21) and (22). The result then directly follows from (A.14) and (A.15), respectively. To prove part (iii), first, substitute (20) and (23) into (24). From this, it is easy to show that

$$
\frac{\partial \tilde{U}}{\partial \kappa}=\frac{\rho}{(1-\rho)^{2}}\left(\frac{\rho-\eta(\sigma-1)}{1-(\kappa+\eta)(\sigma-1)}+\ln \tilde{l}^{R}\right),
$$

where $\tilde{l}^{R}$ is given by (20), and

$$
\frac{\partial \tilde{U}}{\partial \eta}=-\frac{\rho}{(1-\rho)^{2}} \frac{1-\kappa(\sigma-1)-\rho}{1-(\kappa+\eta)(\sigma-1)},
$$

respectively. Observing Assumption 2 confirms part (iii). This concludes the proof. 
Proof of Proposition 3. First, note that a social planner who does not know the realizations of the $\gamma^{\prime}$ s in advance will choose a symmetric solution for R\&D labor input, i.e., $l_{t-1}^{R}(i)=l_{t-1}^{R}$ for all $i$, and will set $l_{t-1}^{M}(i)=l^{M *} \equiv 0, t>0$. Thus, the social planner has to observe the resource constraint $\int_{0}^{n_{t-1}} l_{t-1}^{P}(i) d i+n_{t}\left(l_{t-1}^{R}+f\right)=L$ for all $t>0$, according to (E5). Moreover, as noted by Young (1998), the socially optimal plan will also be one with immediate implementation of a steady state. Thus, using (A.4), the resource constraint implies $E(\sigma-1) / \sigma=L-n\left(l^{R}+f\right)$. Using intertemporal welfare (A.13) together with the latter expression, one finds that the social planner's problem is to solve

$$
\max _{n, l^{R}}\left\{\ln \left[L-n\left(l^{R}+f\right)\right]+\rho\left(\frac{1}{\sigma-1} \ln n+\frac{1}{1-\rho} \ln g\left(l^{R}\right)\right)\right\} .
$$

Straightforward manipulations of the corresponding first-order conditions (which are also sufficient for a social optimum) and observing (6) then lead to $l^{R *}$ and $n^{*}$ as given by (25) and (27), respectively.

Proof of Lemma 2. Under (28), the expected firm value becomes

$$
\frac{p_{t}(i)-1 / b}{1+r_{t}} \mathbb{E}\left(x_{t}^{D} \mid l_{t-1}^{R}(i), l_{t-1}^{M}(i)\right)-(1-\tau) l_{t-1}^{R}(i)-l_{t-1}^{M}(i)-f-\Theta .
$$

Using (16) and (A.2), one finds analogously to the first-order conditions (17), (18), and the free entry condition (E3) that

$$
\begin{gathered}
\frac{\rho}{\sigma} \frac{E_{t-1}}{n_{t}}(\sigma-1) \kappa=(1-\tau) l_{t-1}^{R} \\
\frac{\rho}{\sigma} \frac{E_{t-1}}{n_{t}} \frac{(\sigma-1) \eta}{\bar{l}_{t-1}^{M}}=1
\end{gathered}
$$

and

$$
\frac{\rho}{\sigma} \frac{E_{t-1}}{n_{t}}=(1-\tau) l_{t-1}^{R}+l_{t-1}^{M}+f+\Theta
$$

respectively. Moreover, using (A.4), the labor market clearing condition (E5) implies

$$
\frac{\sigma-1}{\sigma} E_{t-1}+n_{t}\left(l_{t-1}^{R}+l_{t-1}^{M}+f\right)=L .
$$


Using (A.20)-(A.23) to solve for the four unknowns $E_{t-1}=\tilde{E}, n_{t}=\tilde{n}, l_{t-1}^{R}=\tilde{l}^{R}$ and $\bar{l}_{t-1}^{M}=l_{t-1}^{M}=\tilde{l}^{M}, t>0$, one obtains after some manipulations:

$$
\begin{gathered}
\tilde{E}=\frac{\rho L(1-\tau)(f+\Theta)}{(\sigma-1)(1-\tau)(f+\Theta)+\rho\{(\sigma-1)[\kappa+\eta(1-\tau)] \Theta+[1-\tau(1-\kappa(\sigma-1))] f\}}, \\
\tilde{n}=\frac{\sigma L[1-(\kappa+\eta)(\sigma-1)](1-\tau)}{(\sigma-1)(1-\tau)(f+\Theta)+\rho\{(\sigma-1)[\kappa+\eta(1-\tau)] \Theta+[1-\tau(1-\kappa(\sigma-1))] f\}}, \\
\tilde{l}^{R}=\frac{\kappa(\sigma-1)(f+\Theta)}{(1-\tau)[1-(\kappa+\eta)(\sigma-1)]}, \\
\tilde{l}^{M}=\frac{\eta(\sigma-1)(f+\Theta)}{1-(\kappa+\eta)(\sigma-1)} .
\end{gathered}
$$

Observing Assumption 2, Lemma 2 directly follows from (A.25)-(A.27).

Remark 3. (Balanced budget). It remains to confirm that the government's budget is automatically balanced if the considered transfer (or tax) to firms under scheme (28) is financed by a lump-sum tax (or subsidy) of consumers. To see this, note that the lump-sum tax for consumers is given by $\Psi_{t} \equiv n_{t+1}\left(\tau l_{t}^{R}-\Theta\right)$. Using (14) and (A.1), equilibrium condition (E6) implies $\left(1+r_{t}\right) A_{t}=E_{t} / \sigma$. Advancing one period and using $1+r_{t}=1 / \rho$ from Lemma 1 , one finds $A_{t+1}=\rho E_{t+1} / \sigma$. Substituting these expressions into the budget constraint $A_{t+1}=\left(1+r_{t}\right) A_{t}+L-E_{t}-\Psi_{t}, t \geq 0$, we have $E_{t}(\sigma-1) / \sigma+\rho E_{t+1} / \sigma=L-\Psi_{t}$. It remains to be shown that this is consistent with equilibrium conditions (E3) and (E5). Combining (A.2) and (A.19), the free entry condition (E3) implies that

$$
\begin{aligned}
\rho E_{t+1} / \sigma & =n_{t}\left((1-\tau) l_{t-1}^{R}+l_{t-1}^{M}+f+\Theta\right) \\
& =n_{t}\left(l_{t-1}^{R}+l_{t-1}^{M}+f\right)-\Psi_{t} .
\end{aligned}
$$

Finally, combine this expression with (A.23) (which has been derived from (E5)) to confirm $E_{t}(\sigma-1) / \sigma+\rho E_{t+1} / \sigma=L-\Psi_{t}$. This proves the claim.

Proof of Proposition 4. Substituting the expressions for $\tilde{E}, \tilde{n}$ and $\tilde{l}^{R}$ from (A.24), (A.25) and (A.26), respectively, into (A.13) reveals that $\left(\tau^{*}, \Theta^{*}\right)$ solves 


$$
\begin{aligned}
& \max _{(\tau, \Theta)} \tilde{u} \equiv\left(1+\frac{\rho(1-\rho-\kappa(\sigma-1))}{(1-\rho)(\sigma-1)}\right) \ln (1-\tau)+ \\
& \left(1+\frac{\rho \kappa}{1-\rho}\right) \ln (f+\Theta)-\left(1+\frac{\rho}{\sigma-1}\right) \times \\
& \ln \{(\sigma-1)(1-\tau)(f+\Theta)+\rho[(\sigma-1)(\kappa+\eta(1-\tau)) \Theta+(1-\tau(1-\kappa(\sigma-1))) f]\} .
\end{aligned}
$$

Tedious manipulations of the corresponding first-order conditions imply that

$$
\begin{gathered}
\tau^{*}=\frac{\rho(1+\eta)}{1+\rho \eta} \\
=f \frac{\kappa \rho(\sigma-1)-\eta[(\sigma-1)(1-\rho)+\rho(1-\kappa(\sigma-1)-\rho)]}{(1-\kappa(\sigma-1)-\rho)(1+\rho \eta)} .
\end{gathered}
$$

By substituting $\tau=\tau^{*}$ and $\Theta=\Theta^{*}$ from (A.29) and (A.30), respectively, into both (A.25) and (A.26), setting $\eta=0$, and observing (25) and (27), one can show that $\tilde{l}^{R}\left(\tau^{*}, \Theta^{*}\right)=l^{R *}$ and $\tilde{n}\left(\tau^{*}, \Theta^{*}\right)=n^{*}$. This confirms part (i) of Proposition 4. To confirm part (ii), use (A.30) and observe $1-\kappa(\sigma-1)-\rho>0$ from part (ii) of Assumption 2. Finally, as $0<\rho<1$, part (iii) directly follows from (A.29).

Proof of Proposition 5. In equilibrium, for all $t \geq 0, l_{t}^{R}(i)=l_{t}^{R}=\tilde{l}^{R}, i \in \mathcal{N}_{t+1}$, and $n_{t+1}=\tilde{n}$. Thus, using (32), we have

$$
\begin{aligned}
\bar{S}_{t-1} & =\bar{S}_{t-2} g\left(l_{t-2}^{R}\right) n_{t-1}=\ldots \\
& =\bar{S}_{0} g\left(l_{t-2}^{R}\right) g\left(l_{t-3}^{R}\right) \times \ldots \times g\left(l_{1}^{R}\right) g\left(l_{0}^{R}\right) n_{t-1} n_{t-2} \times \ldots \times n_{1} \\
& =\bar{S}_{0} g\left(\tilde{l}^{R}\right)^{t-1} \tilde{n}^{t-1}
\end{aligned}
$$

for any $t>1$. Substituting (A.31) into (A.8) and using both (A.9) and (A.10), one finds that, for any $t \geq 1$,

$$
\tilde{C}_{t}=b \bar{S}_{0} g\left(\tilde{l}^{R}\right)^{t} \tilde{n}^{\frac{1}{\sigma-1}} \tilde{n}^{t-1} \frac{\sigma-1}{\sigma} \tilde{E} .
$$

Moreover, $\tilde{C}_{0}$ is still given by (A.12). Thus, in view of (6), the steady state growth rate is given by $\tilde{\vartheta}=\kappa \ln \tilde{l}^{R}+\ln \tilde{n}$. Using (20) and (22), and observing $0<\kappa<1$, it 
is easy to confirm part (i). To prove part (ii), substitute (A.12) and (A.32) into (1) to show that intertemporal welfare, denoted by $V$, now becomes

$$
V=\tilde{U}+\frac{\rho^{2}}{(1-\rho)^{2}} \ln \tilde{n},
$$

by observing $\sum_{t=1}^{\infty} \rho^{t}(t-1)=\rho^{2} /(1-\rho)^{2}$, where $\tilde{U}$ is given by (A.13). Analogous considerations as for the derivation of (A.18) reveal that the social planner's problem is to solve

$$
\max _{n, l^{R}}\left\{\ln \left[L-n\left(l^{R}+f\right)\right]+\rho\left(\left(\frac{1}{\sigma-1}+\frac{\rho}{1-\rho}\right) \ln n+\frac{1}{1-\rho} \ln g\left(l^{R}\right)\right)\right\} .
$$

Straightforward manipulations of the corresponding first-order conditions and observing (6) then lead to

$$
\begin{gathered}
l^{R * *}=\frac{\kappa(\sigma-1) f}{1-\kappa(\sigma-1)-\rho+\rho(\sigma-1)}, \\
n^{* *}=\frac{\rho L[1-\kappa(\sigma-1)-\rho+\rho(\sigma-1)]}{f\left[(\sigma-1+\rho)(1-\rho)+\rho^{2}(\sigma-1)\right]} .
\end{gathered}
$$

Compare (A.35) and (A.36) with (25) and (27), respectively, to confirm part (ii) of Proposition 5. To confirm part (iii), analogous considerations as for the derivation of $\left(\right.$ A.28) reveals that $\left(\tau^{* *}, \Theta^{* *}\right)$ solves

$$
\begin{aligned}
& \max _{(\tau, \Theta)}\left\{\tilde{u}+\frac{\rho^{2}}{1-\rho}[\ln (1-\tau)-\right. \\
& \ln \{(\sigma-1)(1-\tau)(f+\Theta)+\rho[(\sigma-1)(\kappa+\eta(1-\tau)] \Theta+(1-\tau(1-\kappa(\sigma-1))) f]\}\}
\end{aligned}
$$

where $\tilde{u}$ is given by (A.28). Tedious manipulations of the corresponding first-order conditions imply that $\tau^{* *}=\tau^{*}$, where $\tau^{*}$ is given by (A.29), and

$$
\Theta^{* *}=-f \frac{(1-\kappa) \rho(\sigma-1)+\eta[(\sigma-1)(1-\rho)+\rho(1-\kappa(\sigma-1)-\rho+\rho(\sigma-1))]}{[1-\kappa(\sigma-1)-\rho+\rho(\sigma-1)](\rho \eta+1)} .
$$

By comparing (A.30) with (A.38), one can show that $\Theta^{* *}<\Theta^{*}$ (For this, observe that $1-(\kappa+\eta)(\sigma-1)>0$ from part (i) of Assumption 2 implies $1>\eta(\sigma-1)$ since $\kappa>0$ and $\sigma>1$.) Finally, to confirm $\Theta^{* *}<0, \partial \Theta^{* *} / \partial \eta<0$ and $\partial \Theta^{* *} / \partial \kappa>0$, use (A.38) together with part (ii) of Assumption 2. This concludes the proof. 


\section{References}

Aghion, Philippe and Peter Howitt (1992). A Model of Growth Through Creative Destruction, Econometrica 60, 323-352.

Alvarez-Pelaez, Maria J. and Christian Groth (2003). Too Little or Too Much R\&D?, European Economic Review (forthcoming)

Athey, Susan (2000). Characterizing Properties of Stochastic Objective Functions, MIT (mimeo).

Bresnahan, Timothy F. (1999). Computerisation and Wage Dispersion: An Analytical Reinterpretation, Economic Journal 109, F390-F415.

Cohen, Wesley M. and Steve Klepper (1996). Firm Size and the Nature of Innovation Within Industries: The Case of Process and Product R\&D, Review of Economics and Statistics 78, 232-243.

Cohen, Wesley M. and Richard C. Levin (1989). Empirical Studies of Innovation and Market Structure, In: Schmalensee, R., Willig, R. D. (Eds.), Handbook of Industrial Organization, Vol. II, North-Holland, Amsterdam, ch. 18.

Dixit, Avinash and Joseph E. Stiglitz (1977). Monopolistic Competition and Optimum Product Diversity, American Economic Review 67, 297-308.

Grossman, Gene M. and Elhanan Helpman (1991). Quality Ladders in the Theory of Growth, Review of Economic Studies 58, 43-61.

Grossman, Gene M. and Carl Shapiro (1984). Informative Advertising and Differentiated Products, Review of Economic Studies 51, 63-82.

Howitt, Peter (1999). Steady State Endogenous Growth with Population and R\&D Inputs Growing, Journal of Political Economy 107, 715-730.

Jones, Charles I. (1995). R\&D-Based Models of Economic Growth, Journal of Political Economy 103, 759-784.

Jones, Charles I. (1999). Growth: With or Without Scale Effects?, American Economic Review 89, 139-144.

Jones, Charles I. and John C. Williams (2000). Too Much of a Good Thing? The Economics of Investment in R\&D, Journal of Economic Growth 5, 65-85. 
Konishi, Hideki (1990). Final and Intermediate Goods Taxation in an Oligopolistic Economy with Free Entry, Journal of Public Economics 42, 371-86.

Mueller, Willard F. and Richard T. Rogers (1984). Changes in Market Concentration of Manufacturing Industries 1947-1977, Review of Industrial Organization 1, $1-14$.

Nelson, Phillip (1974). Advertising as Information, Journal of Political Economy $81,729-754$

OECD (1999). Science, Technology and Industry Scoreboard 1999: Benchmarking Knowledge-based Economies, Paris.

Paton, David and Neil Conant (2001). An Introduction to the 1999 Advertising and Industry Survey, Journal of Industrial Economics Notes and Comments.

Romer, Paul (1990). Endogenous Technical Change, Journal of Political Economy 98, S71-S102.

Schonfeld \& Associates (2003). Advertising Ratios and Budgets, Schonfeld \& Associates, Incorporated.

Shaked, Avner and John Sutton (1987). Product Differentiation and Industrial Structure, Journal of Industrial Economics 36, 131-146.

Shapiro, Carl and Hal R. Varian (1999). Information Rules, Harvard Business School Press, Boston.

Shepard, David and Rajeev Batra (1998). The New Direct Marketing, McGrawHill, New York.

Skaperdas, Stergios (1996). Contest Success Functions, Economic Theory 7, 283-290.

Sutton, John (1991). Sunk Costs and Market Structure: Price Competition, Advertising, and the Evolution of Concentration, MIT Press, Cambridge, MA.

Tirole, Jean (1988). The Theory of Industrial Organization, MIT Press, Cambridge, MA.

Young, Alwyn (1998). Growth Without Scale Effects, Journal of Political Economy 106, 41-63. 


\title{
CESifo Working Paper Series
}

\author{
(for full list see www.cesifo.de)
}

938 Sören Blomquist and Vidar Christiansen, Is there a Case for Public Provision of Private Goods if Preferences are Heterogeneous? An Example with Day Care, May 2003

939 Hendrik Jürges, Kerstin Schneider, and Felix Büchel, The Effect of Central Exit Examinations on Student Achievement: Quasi-experimental Evidence from TIMSS Germany, May 2003

940 Samuel Bentolila and Juan F. Jimeno, Spanish Unemployment: The End of the Wild Ride?, May 2003

941 Thorsten Bayindir-Upmann and Anke Gerber, The Kalai-Smorodinsky Solution in Labor-Market Negotiations, May 2003

942 Ronnie Schöb, Workfare and Trade Unions: Labor Market Repercussions of Welfare Reform, May 2003

943 Marko Köthenbürger, Tax Competition in a Fiscal Union with Decentralized Leadership, May 2003

944 Albert Banal-Estañol, Inés Macho-Stadler, and Jo Seldeslachts, Mergers, Investment Decisions and Internal Organisation, May 2003

945 Kaniska Dam and David Pérez-Castrillo, The Principal-Agent Matching Market, May 2003

946 Ronnie Schöb, The Double Dividend Hypothesis of Environmental Taxes: A Survey, May 2003

947 Erkki Koskela and Mikko Puhakka, Stabilizing Competitive Cycles with Distortionary Taxation, May 2003

948 Steffen Huck and Kai A. Konrad, Strategic Trade Policy and Merger Profitability, May 2003

949 Frederick van der Ploeg, Beyond the Dogma of the Fixed Book Price Agreement, May 2003

950 Thomas Eichner and Rüdiger Pethig, A Microfoundation of Predator-Prey Dynamics, May 2003

951 Burkhard Heer and Bernd Süssmuth, Cold Progression and its Effects on Income Distribution, May 2003 
952 Yu-Fu Chen and Michael Funke, Labour Demand in Germany: An Assessment of NonWage Labour Costs, May 2003

953 Hans Gersbach and Hans Haller, Competitive Markets, Collective Decisions and Group Formation, May 2003

954 Armin Falk, Urs Fischbacher, and Simon Gächter, Living in Two Neighborhoods Social Interactions in the LAB, May 2003

955 Margarita Katsimi, Training, Job Security and Incentive Wages, May 2003

956 Clemens Fuest, Bernd Huber, and Jack Mintz, Capital Mobility and Tax Competition: A Survey, May 2003

957 Edward Castronova, The Price of 'Man' and 'Woman': A Hedonic Pricing Model of Avatar Attributes in a Synthetic World, June 2003

958 Laura Bottazzi and Marco Da Rin, Financing Entrepreneurial Firms in Europe: Facts, Issues, and Research Agenda, June 2003

959 Bruno S. Frey and Matthias Benz, Being Independent is a Great Thing: Subjective Evaluations of Self-Employment and Hierarchy, June 2003

960 Aaron Tornell and Frank Westermann, Credit Market Imperfections in Middle Income Countries, June 2003

961 Hans-Werner Sinn and Wolfgang Ochel, Social Union, Convergence and Migration, June 2003

962 Michael P. Devereux, Measuring Taxes on Income from Capital, June 2003

963 Jakob de Haan, Jan-Egbert Sturm and Bjørn Volkerink, How to Measure the Tax Burden on Labour at the Macro-Level?, June 2003

964 Harry Grubert, The Tax Burden on Cross-Border Investment: Company Strategies and Country Responses, June 2003

965 Kirk A. Collins and James B. Davies, Measuring Effective Tax Rates on Human Capital: Methodology and an Application to Canada, June 2003

966 W. Steven Clark, Using Micro-Data to Assess Average Tax Rates, June 2003

967 Christopher Heady, The 'Taxing Wages' Approach to Measuring the Tax Burden on Labour, June 2003

968 Michael P. Devereux and Alexander Klemm, Measuring Taxes on Income from Capital: Evidence from the UK, June 2003

969 Bernhard Eckwert and Itzhak Zilcha, The Effect of Better Information on Income Inequality, June 2003 
970 Hartmut Egger and Josef Falkinger, The Role of Public Infrastructure for Firm Location and International Outsourcing, June 2003

971 Dag Morten Dalen and Trond E. Olsen, Regulatory Competition and Multi-national Banking, June 2003

972 Matthias Wrede, Tax Deductibility of Commuting Expenses and Residential Land Use with more than one Center, June 2003

973 Alessandro Cigno and Annalisa Luporini, Scholarships or Student Loans? Subsidizing Higher Education in the Presence of Moral Hazard, June 2003

974 Chang Woon Nam, Andrea Gebauer and Rüdiger Parsche, Is the Completion of EU Single Market Hindered by VAT Evasion?, June 2003

975 Michael Braulke and Giacomo Corneo, Capital Taxation May Survive in Open Economies, July 2003

976 Assar Lindbeck, An Essay on Welfare State Dynamics, July 2003

977 Henrik Jordahl and Luca Micheletto, Optimal Utilitarian Taxation and Horizontal Equity, July 2003

978 Martin D. D. Evans and Richard K. Lyons, Are Different-Currency Assets Imperfect Substitutes?, July 2003

979 Thorsten Bayindir-Upmann and Frank Stähler, Market Entry Regulation and International Competition, July 2003

980 Vivek Ghosal, Firm and Establishment Volatility: The Role of Sunk Costs, Profit Uncertainty and Technological Change, July 2003

981 Christopher A. Pissarides, Unemployment in Britain: A European Success Story, July 2003

982 Wolfgang Buchholz, Richard Cornes, and Wolfgang Peters, On the Frequency of Interior Cournot-Nash Equilibria in a Public Good Economy, July 2003

983 Syed M. Ahsan and Panagiotis Tsigaris, Choice of Tax Base Revisited: Cash Flow vs. Prepayment Approaches to Consumption Taxation, July 2003

984 Campbell Leith and Jim Malley, A Sectoral Analysis of Price-Setting Behavior in US Manufacturing Industries, July 2003

985 Hyun Park and Apostolis Philippopoulos, Choosing Club Membership under Tax Competition and Free Riding, July 2003

986 Federico Etro, Globalization and Political Geography, July 2003

987 Dan Ariely, Axel Ockenfels and Alvin E. Roth, An Experimental Analysis of Ending Rules in Internet Auctions, July 2003 
988 Paola Conconi and Carlo Perroni, Self-Enforcing International Agreements and Domestic Policy Credibility, July 2003

989 Charles B. Blankart and Christian Kirchner, The Deadlock of the EU Budget: An Economic Analysis of Ways In and Ways Out, July 2003

990 M. Hasham Pesaran and Allan Timmermann, Small Sample Properties of Forecasts from Autoregressive Models under Structural Breaks, July 2003

991 Hyun Park, Apostolis Philippopoulos and Vangelis Vassilatos, On the Optimal Size of Public Sector under Rent-Seeking competition from State Coffers, July 2003

992 Axel Ockenfels and Alvin E. Roth, Late and Multiple Bidding in Second Price Internet Auctions: Theory and Evidence Concerning Different Rules for Ending an Auction, July 2003

993 Pierre Salmon, The Assignment of Powers in an Open-ended European Union, July 2003

994 Louis N. Christofides and Chen Peng, Contract Duration and Indexation in a Period of Real and Nominal Uncertainty, July 2003

995 M. Hashem Pesaran, Til Schuermann, Björn-Jakob Treutler, and Scott M. Weiner, Macroeconomic Dynamics and Credit Risk: A Global Perspective, July 2003

996 Massimo Bordignon and Sandro Brusco, On Enhanced Cooperation, July 2003

997 David F. Bradford, Addressing the Transfer-Pricing Problem in an Origin-Basis X Tax, July 2003

998 Daniel Gros, Who Needs Foreign Banks?, July 2003

999 Wolfram Merzyn and Heinrich W. Ursprung, Voter Support for Privatizing Education: Evidence on Self-Interest and Ideology, July 2003

1000 Jo Thori Lind, Fractionalization and the Size of Government, July 2003

1001 Daniel Friedman and Donald Wittman, Litigation with Symmetric Bargaining and TwoSided Incomplete Information, July 2003

1002 Matthew Clarke and Sardar M. N. Islam, Health Adjusted GDP (HAGDP) Measures of the Relationship Between Economic Growth, Health Outcomes and Social Welfare, July 2003

1003 Volker Grossmann, Contest for Attention in a Quality-Ladder Model of Endogenous Growth, August 2003 